\title{
Dual Polarized Monopole Patch Antennas for UWB Applications with Elimination of WLAN Signals
}

\author{
P. $\operatorname{Kumar}^{1 *}$ and J. L. Masa-Campos ${ }^{2}$ \\ ${ }^{1}$ Deptartment of Electronics and Communication Engineering, \\ Jaypee University of Information Technology, Waknaghat, Solan-173234, India \\ ${ }^{2}$ Group of Radio-Frequency, Circuits, Antennas and Systems, \\ Department of Electronics and Communication Technology, \\ Autonoma University of Madrid, Madrid-28049, Spain \\ *corresponding author, E-mail: pradeep.kumar@juit.ac.in
}

\begin{abstract}
This paper presents the design, fabrication and measurement of dual polarized microstrip patch antennas for ultra wideband (UWB) applications with notch at 5-6 GHz band. The proposed antenna rejects the wireless local area network (WLAN) signals and work properly in the entire remaining ultra-wideband. Two antennas are designed for two different frequency bands of ultra wideband and both antennas together produce the entire ultra wideband with notch at $5-6 \mathrm{GHz}$ band. The antennas are fed by a 50 $\Omega$ coaxial probe and the entire design is optimized using CST Microwave Studio. The bandwidth of 3.1-5 GHz is achieved by the optimized design of Antenna- 1 and the bandwidth of $6-10.6 \mathrm{GHz}$ is achieved by the optimized design of Antenna-2. The bandwidth of the optimized combined antenna is $3.1-10.6 \mathrm{GHz}$ with elimination of the $5-6 \mathrm{GHz}$ band. Both antennas are simulated, developed and measured. The simulated and measured results are presented. The two designed dual polarized antennas i.e. Antenna-1 and Antenna-2 can be used for 3.1-5 GHz band and 6-10.6 GHz band dual polarized applications, respectively, and the combined antenna structure can be used for UWB dual polarized applications with elimination of 5-6 $\mathrm{GHz}$ band signals.
\end{abstract}

\section{Introduction}

The wide bandwidth is always a key requirement for the wireless communication systems in order to increase the number of users. For various applications the Federal Communication Commission (FCC) has allotted the wideband spectrum i.e. from 3.1 to $10.6 \mathrm{GHz}$ for the unlicensed use as Ultra Wideband [1-5]. Due to many favorable characteristics like low profile, light weight, low cost etc, microstrip antennas are commonly used in various applications such as wireless communication systems, missile, aircraft etc [67]. The narrow bandwidth is one of the major limitation of the microstrip patch antennas. Hence broadbanding is one of the main challenges to microstrip antenna designers [6]. Ultra-wideband microstrip antenna design requires around 7.5 GHz bandwidth centered at $6.85 \mathrm{GHz}$ which is more than 100 percent bandwidth, and conventional microstrip antennas have only 3-10 percent bandwidth only [7]. The design of microstrip antennas for ultra wide-band applications is under investigation. For the ultra wide-band applications many antennas have been designed and studied [8-12]. However it is necessary to avoid the interferences from wireless local network signals at 5-6 GHz [13-15]. Polarization of the antenna plays a key role in the wireless communication system. For better signal quality the transmitting and receiving antennas should be aligned in same polarization direction. Using antenna polarization diversity the capacity of the wireless communication system can be increased and using dual polarized antennas at transmitter and receiver the capacity of the wireless communication system can be doubled [7, 16]. Also the dual polarized field in perpendicular direction with $90^{\circ}$ phase difference produces circularly polarized field which minimizes the path loss in the wireless communication systems[17-20].

The design of dual polarized microstrip patch antenna for ultra wideband applications with elimination of WLAN signals is presented in this paper. Two orthogonal monopoles are used to achieve dual polarization and two different antennas are designed for the two different frequency bands of the ultra wideband range to achieve the entire ultra wideband operation with notch at $5-6 \mathrm{GHz}$ band. The presented antenna structure is designed for two different frequency bands, hence it provides extra degree of freedom to design the antenna for various dual polarized applications. Rest of the paper is organized as follows. The geometry of the designed antennas is described in section 2. The dimensions of the designed antennas, simulated results and the measured results of each antenna are presented in section 3 . Finally section 4 concludes the work.

\section{Antenna geometry}

The basic geometrical configuration for each antenna is shown in Fig.1. In this configuration two monopoles are placed in perpendicular position to each other for achieving the dual polarized radiated field. Each monopole antenna radiates the linearly polarized field. The mutually 
perpendicularly located monopoles in the antenna structure radiate two linearly polarized fields in two different directions which are orthogonal to each other. Hence the designed structure with two perpendicular monopoles radiates the dual orthogonal polarized field. Each monopole is fed by $50 \Omega$ coaxial probe as shown in Fig. 1. The length of the first and second part of the monopole is $L_{1}$ and $L_{2}$, respectively and the width of the first and second part of the monopole is $w_{1}$ and $w_{2}$, respectively. The length and width of the ground plane for each monopole are $L_{3}$ and $w_{3}$, respectively. The idea of using two different parts in each monopole is that the first part of the monopole acts as a matching network in order to minimize the return loss and the second part acts as monopole with approximately length of quarter wavelength. Both monopoles are identical to each other. The height and the dielectric constant of the substrate is $h$ and $\epsilon_{r}$, respectively.
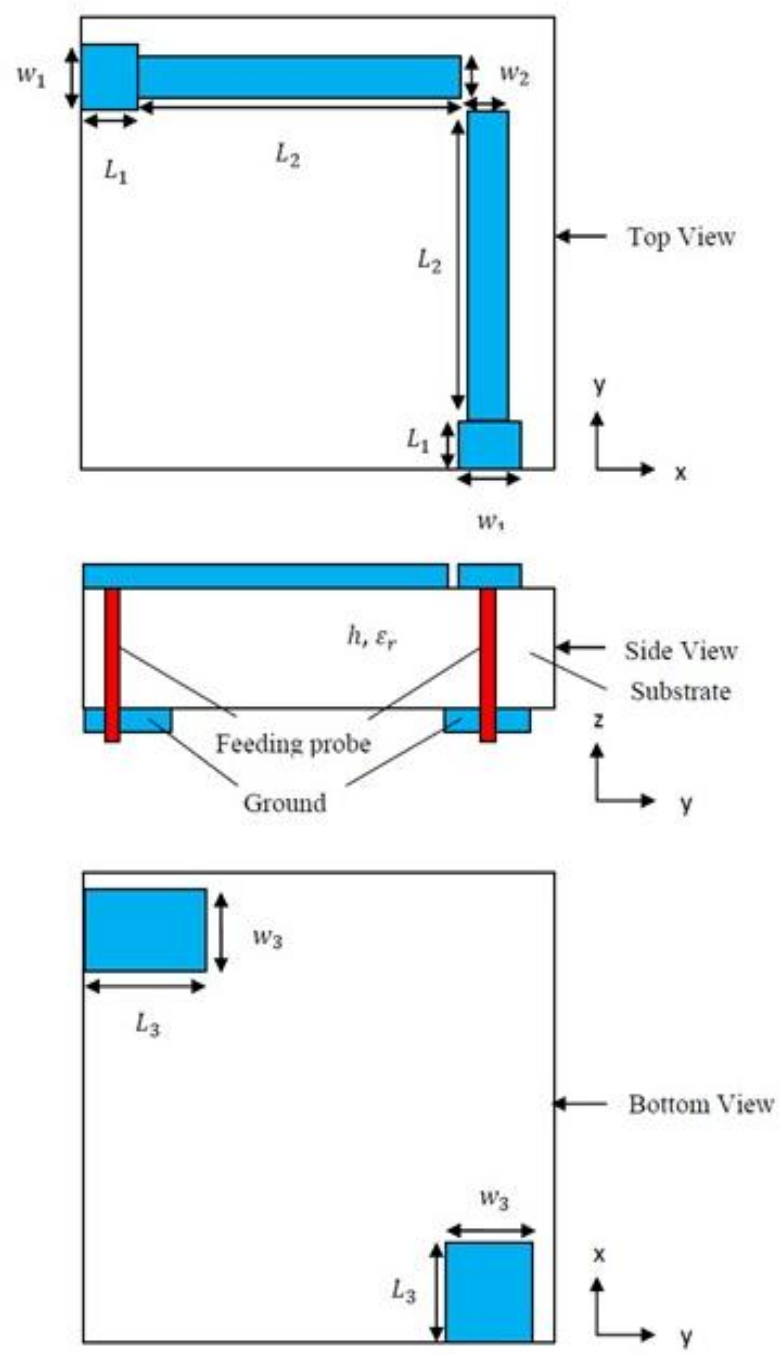

Fig. 1: Geometry of the antenna.

\section{Simulation, fabrication and measurement}

In order to achieve the ultra wideband operation, Antenna1 and Antenna-2 are designed for the lower frequency band and the upper frequency band of the ultra wideband, respectively. The design of each antenna is optimized using CST Microwave Studio. With the optimized dimensions, both antennas are fabricated and the photographs of the fabricated antennas are shown in Fig 2. The developed Antenna-1 and Antenna-2 are shown in Fig. 2(a) and in Fig. 2(b), respectively. The development of the combined antenna structure is depicted in Fig. 2(c). The optimized dimensions of each antenna of Fig. 2 are given in Table I. The thickness $(h)$ and the dielectric constant $\left(\epsilon_{r}\right)$ of the substrate for each antenna are $1.58 \mathrm{~mm}$ and 3.9 , respectively. The thickness of each monopole patch in each antenna is taken $0.01 \mathrm{~mm}$.

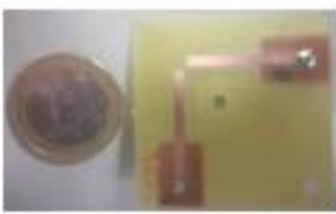

Top View

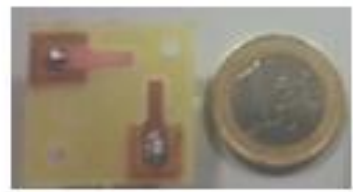

Top View

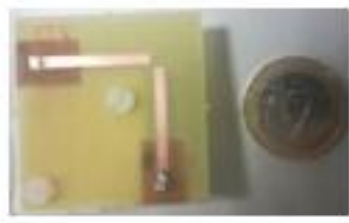

Top View

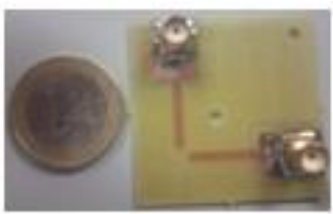

Bottom View

(a)

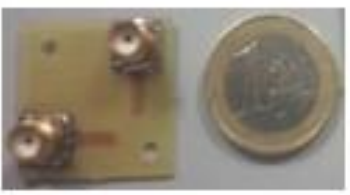

Bottom View

(b)

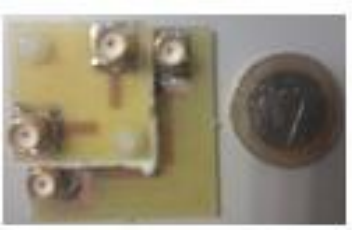

Bottom View (c)

Fig. 2: Photographs of fabricated antennas, (a) Antenna-1, (b) Antenna-2, (c) Combined antenna.

Table I: Dimensions of the Antennas

\begin{tabular}{|l|l|l|l|l|l|}
\hline S. No. & Dimensions & $\begin{array}{l}\text { Antenna 1 } \\
\text { of Fig. 2(a) }\end{array}$ & $\begin{array}{l}\text { Antenna 2 } \\
\text { of Fig. 2(b) }\end{array}$ & \multicolumn{2}{|c|}{$\begin{array}{l}\text { Combined Antenna } \\
\text { (separation between } \\
\text { antennas=5.99 mm) }\end{array}$} \\
\cline { 3 - 6 } & & & & $\begin{array}{l}\text { Antenna 1 } \\
\text { of Fig. 2(c) }\end{array}$ & $\begin{array}{l}\text { Antenna 2 } \\
\text { of Fig. 2(c) }\end{array}$ \\
\hline 1 & $L_{1}$ & $2.1 \mathrm{~mm}$ & $6.45 \mathrm{~mm}$ & $2.1 \mathrm{~mm}$ & $6.45 \mathrm{~mm}$ \\
\hline 2 & $L_{2}$ & $22.3 \mathrm{~mm}$ & $6.5 \mathrm{~mm}$ & $22.3 \mathrm{~mm}$ & $6.5 \mathrm{~mm}$ \\
\hline 3 & $L_{3}$ & $12.9 \mathrm{~mm}$ & $8.875 \mathrm{~mm}$ & $12.9 \mathrm{~mm}$ & $8.875 \mathrm{~mm}$ \\
\hline 4 & $w_{1}$ & $3 \mathrm{~mm}$ & $3.4 \mathrm{~mm}$ & $3 \mathrm{~mm}$ & $3.4 \mathrm{~mm}$ \\
\hline 5 & $w_{2}$ & $2 \mathrm{~mm}$ & $2.2 \mathrm{~mm}$ & $2 \mathrm{~mm}$ & $2.2 \mathrm{~mm}$ \\
\hline 6 & $w_{3}$ & $9 \mathrm{~mm}$ & $8.3 \mathrm{~mm}$ & $9 \mathrm{~mm}$ & $8.3 \mathrm{~mm}$ \\
\hline
\end{tabular}

Each monopole is fed by $50 \Omega$ coaxial probe feeding. The type of coaxial connector used in simulation and fabrication of the structure is shown in Fig 3(a) and Fig. 3(b), 
respectively. In the simulated model similar coaxial connector is used in order to minimize the deviation between simulated and measured results. To use the coaxial connector of Fig 3(b) all the four legs have been cut and the length of the inner conductor is cut in order to just touch the monopole, however one hole of inner conductor's size is made in each monopole and using proper soldering the inner conductor is connected to the monopole. The two different antennas are loaded together as shown in Fig. 2(c). Due to mutual coupling effect between the antennas the behavior of each antenna in the combined antenna structure is not same as shown by them individually. Hence the separation between the two antennas are optimized to achieve the desired specifications. The optimized gap-distance between the bottom surface of the upper antenna (Antenna-1) and the top surface of the lower antenna (Antenna-2) is 5.99 $\mathrm{mm}$.

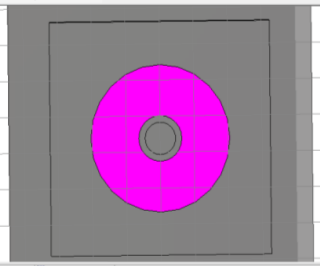

(a)

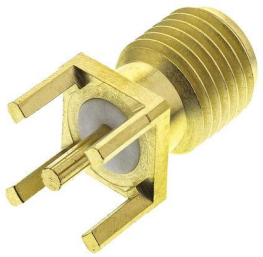

(b)
Fig. 3: $50 \Omega$ coaxial connector used, (a) in simulation (b) in fabrication.

The reflection coefficient and the radiation patterns of each antenna (Antenna-1 and Antenna-2) and the combined antenna structure are measured. The simulated and the measured reflection coefficient of Antenna-1 is shown in Fig. 4. From this figure it can be noted that the bandwidth of the simulated antenna is $3.1-5 \mathrm{GHz}$ (46.9 percent). However there is little deviation between the measured and simulated reflection coefficient due to the two major reasons. Firstly, in the measurement setup (reflection coefficient and radiation pattern) only one monopole is fed and the other monopole(s) are connected with $50 \Omega$ impedance matching pads (metallic). In the individual antennas i.e. Antenna-1 and Antenna- 2 one impedance matching pad is used while in the combined structure three impedance matching pads are used. From Fig. 5 it is clear that the length of the impedance matching pad is bigger in size as compared to the size of the coaxial probe. Also the ground plane in the structure is of smaller size. Hence the presence of impedance matching pads in the measurement setup disturbs the radiated fields by the antenna and other parameters. Hence it causes the deviation between the simulated and the measured results as in simulation all the monopoles are fed by the $50 \Omega$ coaxial connectors. Secondly, the deviation between the simulated and the measured results is due to connector losses.

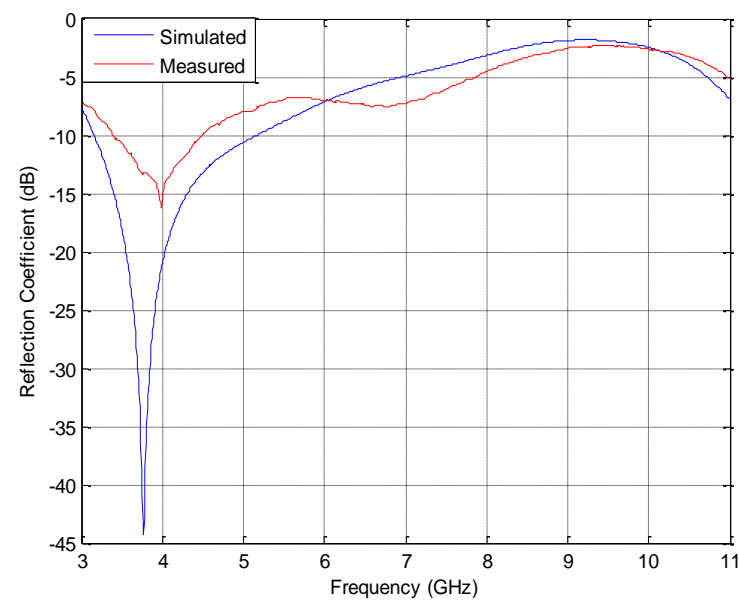

Fig. 4: Reflection coefficient of Antenna-1.

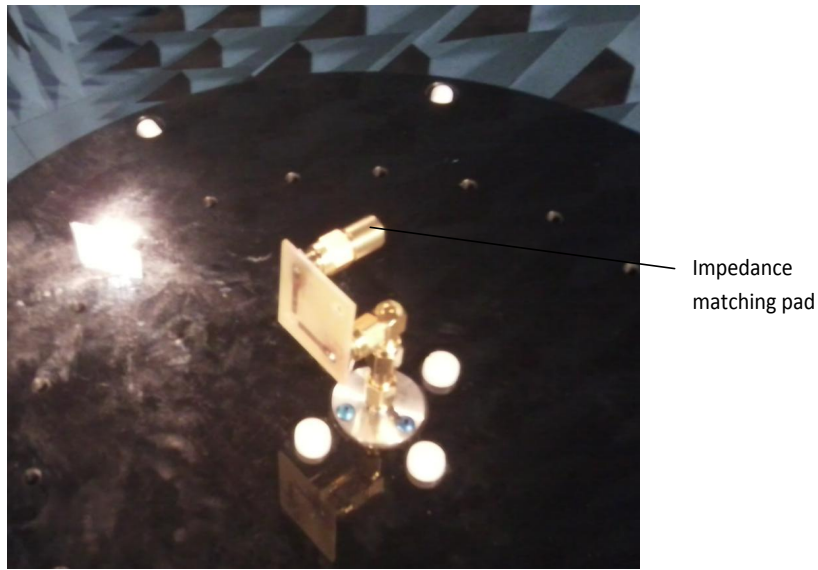

Fig. 5: Measurement setup of radiation pattern.

Fig. 6 shows the simulated voltage standing wave ratio (VSWR) of Antenna-1. From VSWR versus frequency plot it is clear that the value of VSWR is less than 2 thought the frequency band of interest. However there is some deviation between the VSWR of the independent antenna and the antenna in combined structure. It is due to the mutual coupling effect between two antennas.

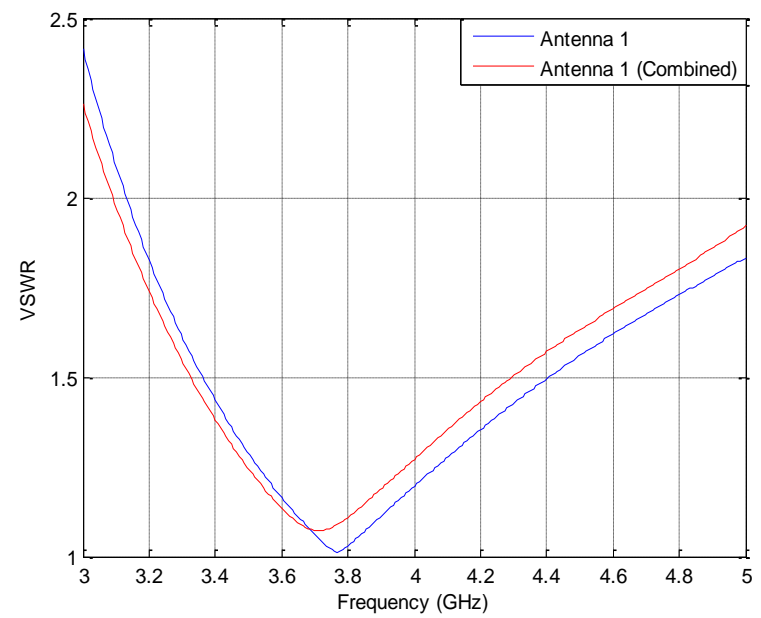

Fig. 6: VSWR of Antenna-1. 
The simulated real and imaginary part of the input impedance of Antenna-1 is depicted in Fig. 7. The real part of the input impedance is maximum and closed to 50 $\Omega$ and the imaginary part is approximately zero near about the resonant frequency of the antenna. The deviation between the input impedance of individual antenna and the input impedance of the antenna in combined structure is due to mutual coupling effect between the antennas in the combined structure.

The simulated and measured reflection coefficient of Antenna-2 are shown in Fig. 8. From this figure it can be observed that the frequency band $6-10.6 \mathrm{GHz}$ is achieved by this antenna. The reasons for the deviation between the simulated and the measured results are same as explained for Antenna-1. However the deviation between the simulated and the measured results is little higher for this antenna as compared to the Antenna- 1 and the reason for this is that the Antenna-2 is smaller in size as compared to Antenna-1. Hence the size of the impedance matching pads is larger with respect to the size of Antenna-2 as compared to Antenna-1. So effect of impedance matching pads is more in Antenna-2 as compared to Antenna-1.

The VSWR versus frequency for Antenna-2 is shown in Fig. 9. It is clear that the value of VSWR is less than 2 throughout the entire frequency range of interest. There is little deviation between the values of VSWR of independent antenna and the antenna in the combined structure due to mutual coupling effect between the Antenna-1 and Antenna-2. Fig. 10 shows the simulated real and imaginary part of the input impedance of Antenna-2. The value of real part of the input impedance is closed to $50 \Omega$ and imaginary part of the input impedance is closed to zero near about resonant frequency of the antenna.

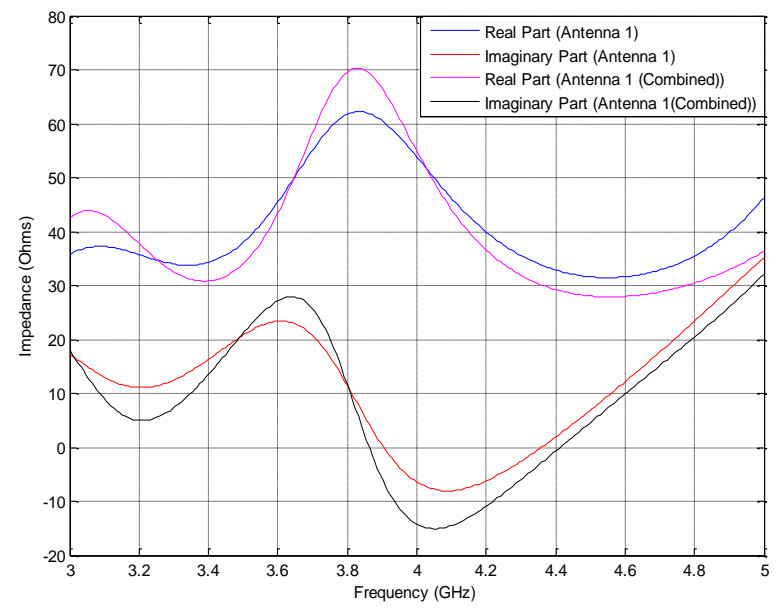

Fig. 7: Input impedance of Antenna-1.

For the design objective to eliminate WLAN signals from UWB band, the Antenna-1 is designed for less than $5 \mathrm{GHz}$ frequencies of UWB and Antenna-2 is designed for $6 \mathrm{GHz}$ and above frequency range of UWB. With this objective the designed and developed two antennas are loaded together to achieve the UWB operation with elimination of WLAN signals at 5-6 GHz band.

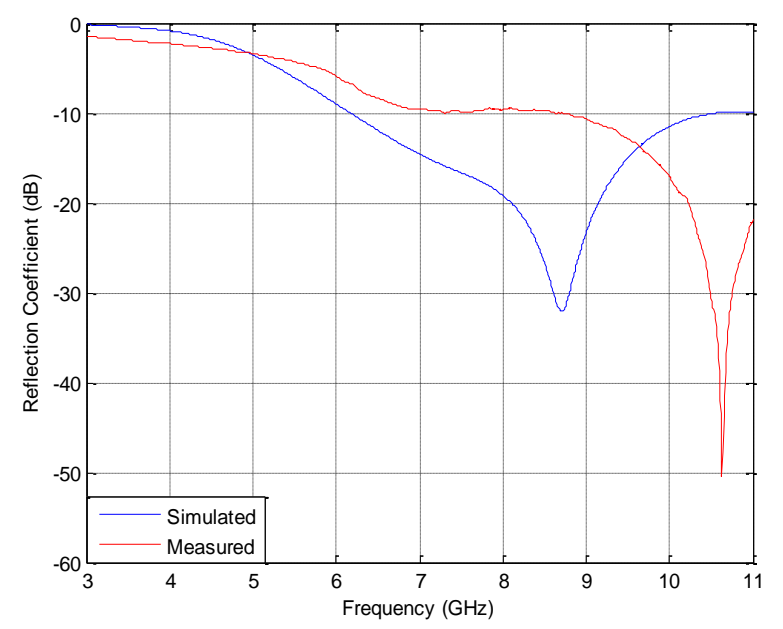

Fig. 8: Reflection coefficient of Antenna-2.

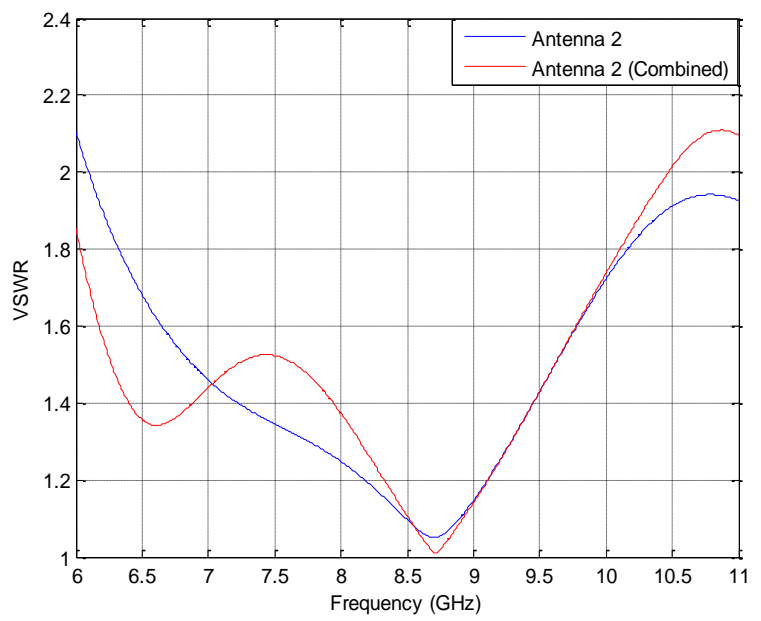

Fig.9:VSWR of Antenna-2.

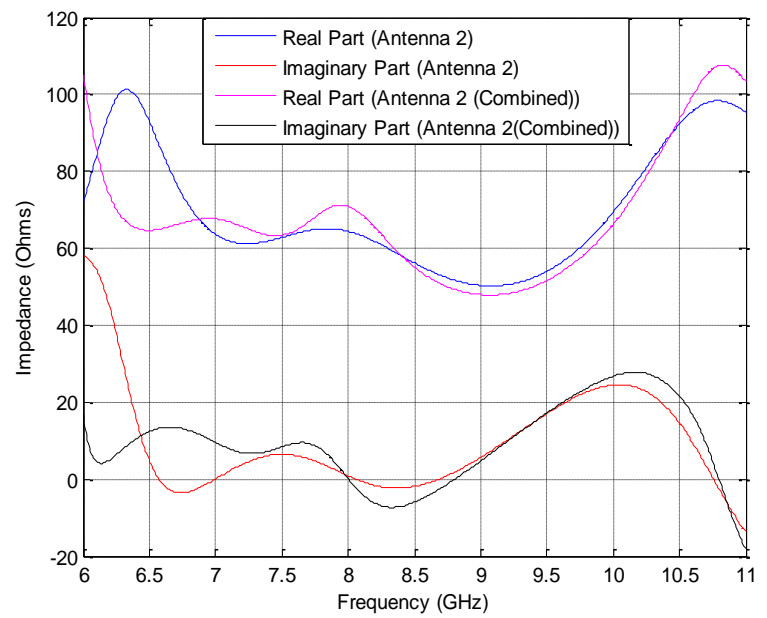

Fig. 10: Input impedance of Antenna-2.

The combined antenna is simulated and measured. The simulated and measured reflection coefficient of the combined antenna is shown in Fig.11. It can be observed from this figure that the reflection coefficient is less than $-10 \mathrm{~dB}$ for the entire range of ultra wideband except 5-6 
GHz. From the reflection coefficient curves of the combined antenna it can be noted that the reflection coefficient of Antenna-1 and Antenna-2 is less than $-10 \mathrm{~dB}$ for the frequency range $3.12-5 \mathrm{GHz}$ and $5.96-10.32 \mathrm{GHz}$, respectively. In the combined structure the reflection coefficient of each antenna is greater than $-10 \mathrm{~dB}$ for the frequency range 5-6 GHz. However there is little deviation between the measured and the simulated reflection coefficient for both antennas and deviation is more for Antenna-2 as compared to Antenna-1. The reason for the deviation between the simulated and the measured results is same as explained for Antenna-1 and Antenna-2. In the measurement system of the combined antenna only one port is fed and the other remaining ports are connected with $50 \Omega$ matching impedance pads. The effect of these impedance matching pads is more in case of high frequency antenna as it is smaller in size, that is why the deviation of measured reflection coefficient from simulated reflection coefficient is more for high frequency band antenna i.e Antenna-2.

The simulated and measured radiation patterns of Antenna1, Antenna-2, and the combined antenna are shown in Fig. 12, Fig. 13 and in Fig. 14, respectively. The radiation patterns of each antenna show the omnidirectional behavior of antennas. The reason for deviation between the measured and the simulated radiation patterns is the presence of $50 \Omega$ matching pads in measurement setup and connector losses as explained earlier.

The various parameters such as resonant frequency, bandwidth and gain of each antenna is summarized in Table II. The directivity and the efficiency of each antenna are shown in Fig. 15 and in Fig. 16, respectively. A little deviation between directivity of the individual antennas and the antennas in combined antenna is observed and it is due to mutual coupling effect between two antennas in the combined structure. The two dual polarized antennas i.e. Antenna-1 and Antenna-2 are designed, developed and measured for two different bands of UWB. These two combined antennas can be used for dual polarized UWB applications with elimination of WLAN signals.

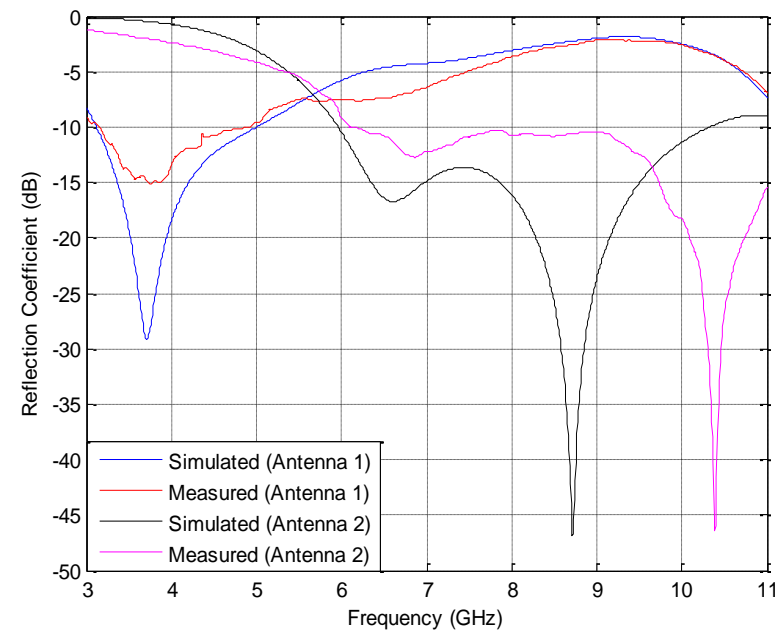

Fig. 11: Reflection coefficient of the combined antenna.
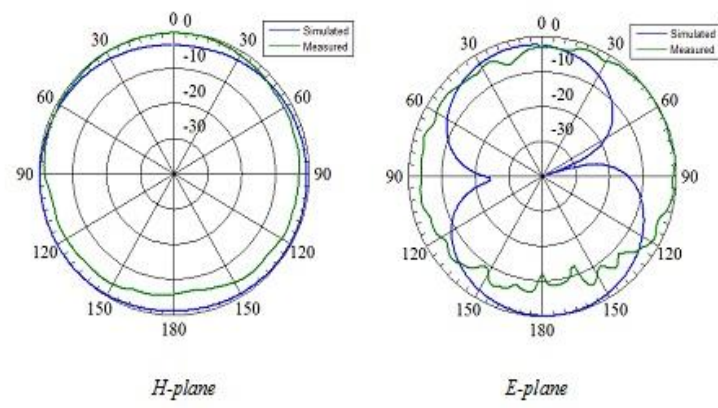

Fig. 12: Radiation pattern of Antenna-1 at $5 \mathrm{GHz}$.

Table II: Antenna parameters

\begin{tabular}{|l|l|l|l|l|l|}
\hline S. No. & Parameter & \multicolumn{5}{|c|}{ Range/Value } \\
\cline { 3 - 6 } & & Antenna 1 & Antenna 2 & \multicolumn{2}{|c|}{ Combined Antenna } \\
\cline { 5 - 6 } & & & & Antenna 1 & Antenna 2 \\
\hline 1 & Bandwidth & $3.16 \mathrm{GHz}-$ & $6.176 \mathrm{GHz}-$ & $3.12 \mathrm{GHz}-$ & $5.96 \mathrm{GHz}-$ \\
$5.168 \mathrm{GHz}$ & $10.568 \mathrm{GHz}$ & $5 \mathrm{GHz}$ & $10.32 \mathrm{GHz}$ \\
\hline 2 & $\begin{array}{l}\text { Center } \\
\text { Frequency }\end{array}$ & $4.164 \mathrm{GHz}$ & $8.375 \mathrm{GHz}$ & $4.06 \mathrm{GHz}$ & $8.14 \mathrm{GHz}$ \\
\hline 3 & $\begin{array}{l}\text { Frequency } \\
\text { Ratio }\end{array}$ & $1.635: 1$ & $1.71: 1$ & $1.6: 1$ & $1.73: 1$ \\
\hline 4 & $\begin{array}{l}\text { Percentage } \\
\text { Bandwidth }\end{array}$ & $48.22 \%$ & $52.44 \%$ & $46.3 \%$ & $53.56 \%$ \\
\hline 5 & $\begin{array}{l}\text { Gain }(4 \\
\text { GHz }\end{array}$ & $2.559 \mathrm{dBi}$ & - & $3.356 \mathrm{dBi}$ & - \\
\hline 6 & $\begin{array}{l}\text { Gain }(7) \\
\text { GHz }\end{array}$ & - & $3.34 \mathrm{dBi}$ & - & $5.16 \mathrm{dBi}$ \\
\hline 7 & $\begin{array}{l}\text { Gain }(8 \\
\text { GHz) }\end{array}$ & - & $4.257 \mathrm{dBi}$ & - & $4.18 \mathrm{dBi}$ \\
\hline 8 & $\begin{array}{l}\text { Gain }(10 \\
\text { GHz) }\end{array}$ & - & $5.346 \mathrm{dBi}$ & - & $6.038 \mathrm{dBi}$ \\
\hline
\end{tabular}
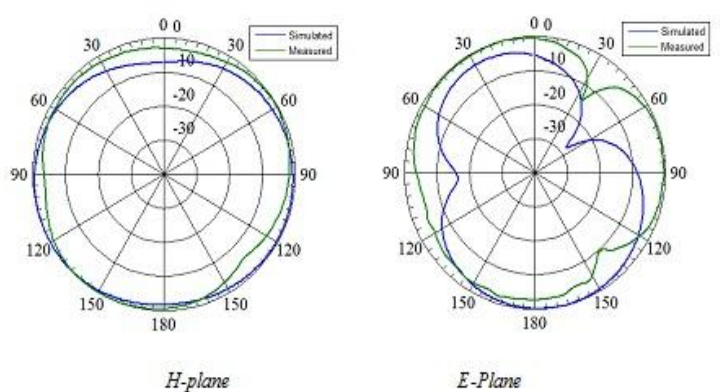

(a)
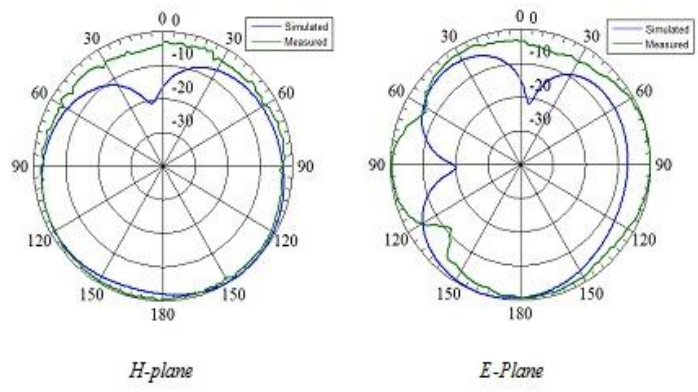

(b)

Fig.13:Radiation pattern of Antenna-2 at (a) $7 \mathrm{GHz}$ (b) 9 $\mathrm{GHz}$ 


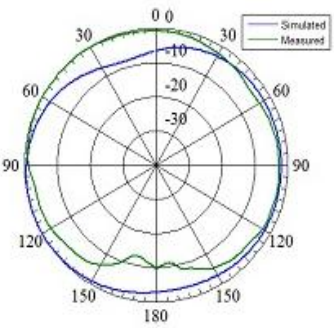

H-plane

(a)

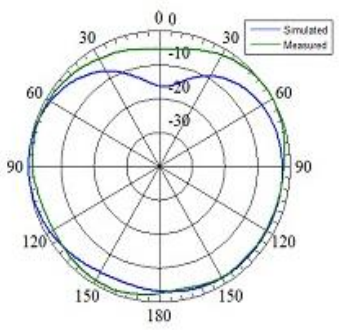

H-plane

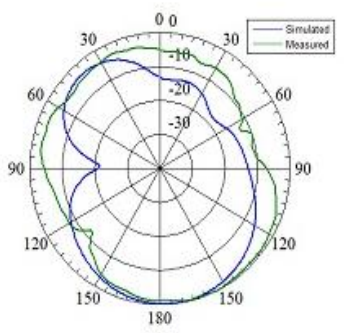

E-Plane

(b)

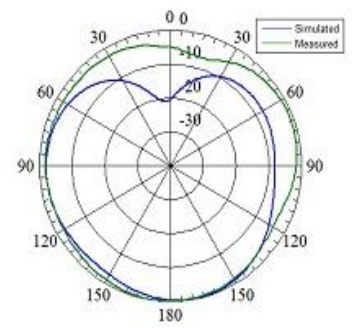

H-plane

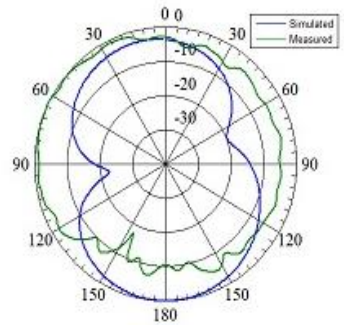

E-Plane

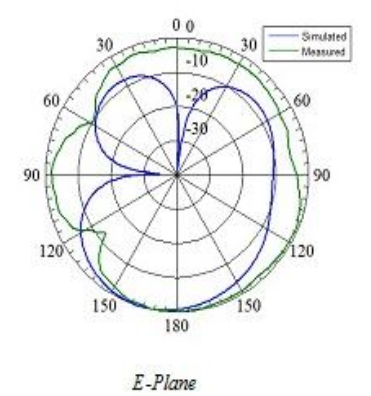

(c)

Fig. 14: Radiation pattern of the combined antenna at (a)5 $\mathrm{GHz}(\mathrm{b}) 7 \mathrm{GHz}$ (c) $9 \mathrm{GHz}$.

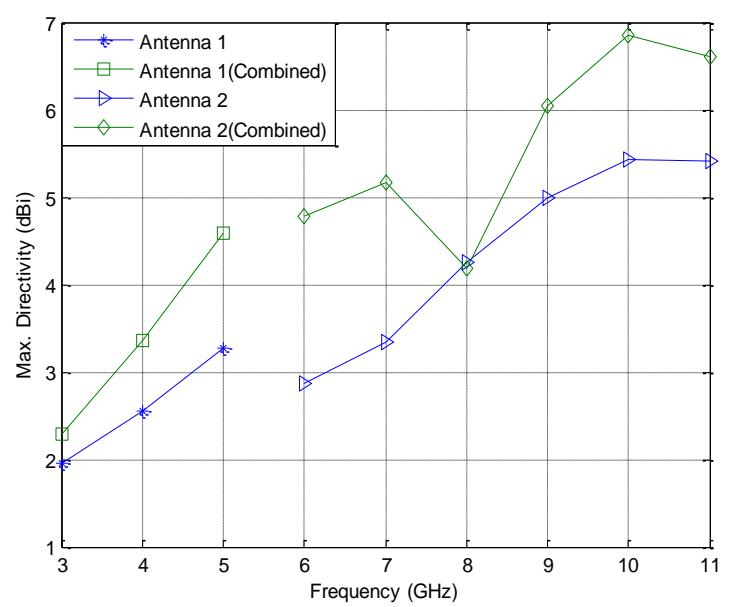

Fig. 15: Maximum directivity of the antennas.

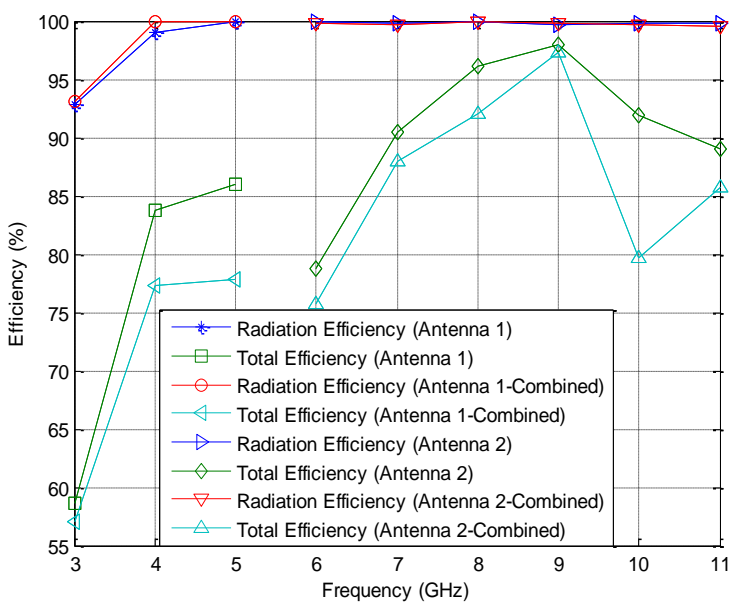

Fig. 16: Efficiency of the antennas.

\section{Conclusion}

In this paper, dual polarized microstrip patch antennas have been designed, developed and measured for ultra wideband applications with notch at 5-6 GHz to eliminate WLAN signals. Two antennas have been presented for two different frequency bands of the ultra wideband. The combined antenna with the optimized design of each antenna and the gap-distance between the antennas gives the entire frequency range of ultra wideband with notch at $5-6 \mathrm{GHz}$ band and eliminates WLAN signals. The simulated as well as measured results have been presented. The radiation patterns of each antenna show the omnidirectional nature of the antennas. The presented dual polarized antennas are suitable for UWB applications with elimination of $5-6 \mathrm{GHz}$ band signals.

\section{Acknowledgement}

This work is supported by Universidad Autonoma de Madrid and Banco Santander. Likewise, authors thank Universidad Autonoma de Madrid and Banco Santander for being the funding organization of this work.

The authors are also sincerely thankful to the reviewers and editor for their valuable suggestions to improve the quality of the manuscript.

\section{References}

[1] R. A. Scholtz et al., UWB radio deployment challenges, Proc. of IEEE Personal, Indoor and Mobile Radio Conference (IEEE PIMRC) 1: 620-625, 2000.

[2] K. Siwiak and D. McKeown, Ultra-wideband radio technology, John Wieley and Sons, 2004.

[3] C. B. Kim, J. S. Lim, J. S. Jang, Y. H. Jung, H. S. Lee, M. S. Lee, Wideband notched compact UWB antenna, Int. J. of Applied Electromagnetics and Mechanics 28: 101-110, 2008. 
[4] Z.N. Chen, X.H. Wu, H.F. Li, M.Y. Chia, Considerations for source pulses and antennas in UWB radio systems, IEEE Transactions on Antennas and Propagation 52: 1739-1748, 2004.

[5] P. Withington, Ultra-wideband RF-A Tutorial, Presentation to the IEEE 802 Plenary Meeting in Albuquerque, Document IEEE 802.15-00/083r0, 2000.

[6] R. Garg, P. Bhartia, I. Bahl, A. Ittipiboon, Microstrip antenna design handbook, Artrech House Publishers, Boston, 2001.

[7] C. A. Balanis, Antenna theory: analysis and design, Wiley, 2005.

[8] F. Zhu, S.-C. S. Gao, A. T. S. Ho, T. W. C. Brown, J. Li, and J.-D. Xu, Low-profile directional ultra-wideband antenna for see-through-wall imaging applications, Progress In Electromagnetic Research 121: 121-139, 2011.

[9] K.Y. Yazandost, Ultra wideband antenna, IEEE Communication Magazine 42: 529-532, 2004.

[10] R.V.S.R. Krishna, R. Kumar, A circularly polarised planar slot antenna for UWB applications, Int. Journal of Electronics Letters 1: 233-241, 2013.

[11] S. Angelopoulos, A. Z. Anastopoulos, D. I. Kaklamani, A. A. Alexandridis, F. Lazarakis, and K. Dangakis, Circular and elliptical CPW-fed slot and microstrip-fed antennas for ultra wideband applications, IEEE Antennas and Wireless Propagation Letters 5: 294-297, 2006.

[12] P. Kumar, and J. L. Masa-Campos, Dual polarized microstrip patch antennas for ultra-wideband applications, Microwave and Optical Technology Letters 56: 2174-2179, 2014.

[13] A. Elboushi, O. M. Ahmed, and A. R. Sebak, Study of elliptical slot UWB antennas with A 5.0-6.0 GHz band-notch capability, Progress In Electromagnetics Research C 16: 207-222, 2010.

[14] C.-M. Li and L.-H. Ye, Improved dual band-notched UWB slot antenna with controllable notched bandwidths, Progress In Electromagnetics Research 115: 477-493, 2011.

[15] R. Azim, M. T. Islam, J. S. Mandeep, and A. T. Mobashsher, A planar circular ring ultra-wideband antenna with dual band-notched characteristics, Journal of Electromagnetic Waves and Applications 26: 14-15, 2012.

[16] J. L. Masa-Campos and F. Gonzalez-Fernandez, Dual linear/circular polarized plannar antenna with low profile double-layer polarizer of 450 tilted metallic strips for WiMAX applications, Progress In Electromagnetics Research 98: 221-231, 2009.
[17] Q. Liu, J. Shen, J. Yin, H. Liu, and Y. Liu, Compact 0.92/2.45-GHz dual-band directional circularly polarized microstrip antenna for handheld RFID reader applications, IEEE Trans. on Antennas and Propagation 63(9): 3849-3856, 2015.

[18] S. H. Zainud-Deen, S. A. Elhamied and A. Malhat, Integrated millimeter-wave antennas for on-chip communication, Advanced Electromagnetics 5(1): 22-29, 2016.

[19] S. Chakrabarti, Composite feed dual circularly polarized microstrip antenna with improved characterstics, Microwave and Optical Technology Letters 58(2): 283-289, 2016.

[20] L. S. Pereira and M. V. T. Heckler, Dual-band dualpolarized microstrip antenna for $\mathrm{Rx} / \mathrm{Tx}$ terminals for high altitude platforms, 2015 9th European Conference on Antennas and Propagation (EuCAP) : 1-5, 2015. 